\title{
ZINC ALTERS CYTOSKELETAL INTEGRITY AND MIGRATION IN COLON CANCER CELLS
}

\author{
Emil Rudolf, Lada Klvačová, Stanislav John, Miroslav Červinka \\ Charles University in Prague, Faculty of Medicine in Hradec Králové, Czech Republic: Department of Medical Biology \\ and Genetics \\ Summary: Zinc has been shown to have inhibitory effects on proliferation and metabolism of malignant colonocytes. Still, \\ there is no information available concerning putative effects of zinc against motility and migration of colon cancer cells. Using \\ fluorescence microscopy, immunoblotting and microflorimetry we show that treatment with zinc sulfate affected motility, \\ invasiveness, cytoskeletal integrity and expression of selected markers (E-cadherin, catenin, vimentin, tubulin and actin) of \\ invasive SW480 colon tumor cells. These results emphasize the possible multitudinous role of zinc in the process of colon \\ cancer development and hint at the potential of this element in chemoprevention of advanced colorectal carcinoma.
}

Key words: SW480 cells; Migration; Invasion; Cytokeleton; Microtubules

\section{Introduction}

One of the defining features of colon cancer progression is an ability of malignant colonocytes to migrate, to invade the surrounding tissues and eventually to metastasize. All these processes depend on a wide array of molecules and pathways, of which the integrity and functional status cytoskeleton, and in particular of its principle components actin filaments, microtubules and selected intermediate filaments, play an especially important role (14). On the other hand, the functional loss or altered arrangement of individual cytoskeletal components may produce disturbances not only in cell morphology, but it may also affect the locomotion of cells, ultimately leading to enhanced or halted progression of colorectal tumors (2).

Zinc is involved in many aspects of cellular physiology, including structural as well as functional and signaling status of the cell. Zinc deficiency is acknowledged to be associated with growth retardation, neurosensory changes, immune system deficiencies and increased susceptibility to malignant disease (15). Moreover, decreased zinc levels constitute one of the primary risk factors in the development and progression of colorectal tumors (18). It has been reported that zinc regulates the growth of malignant colonocytes by several possible mechanisms, which include $\mathrm{G}_{2} / \mathrm{M}$ phase arrest mediated by a suggested posttranslational regulation of expression of APC protein, ERK-dependent activation of cell cycle inhibitor $\mathrm{p} 21$ and disruption of cell-cell communication as well as microtubule activity (5, 6 ). The effect of zinc on the cytoskeletal integrity of malignant colonic cells is in particular interesting mainly due to the following reasons: firstly, zinc is required for the optimal microtubule polymerization and is an essential part of numerous other proteins often involved in migration, invasion and metastasis (8); secondly, despite changed zinc status, malignant colonic cells at certain stages show increased invasive and metastatic properties.

Considering the reported data on the inhibitory effects of zinc towards colon cancer cells and in particular its effects towards the cytoskeleton, we hypothesized that zincinduced growth inhibition may be preceded or accompanied by a changed cellular migratory status too. We have thus started to investigate cytoskeletal topography as well as migration and invasiveness of SW480 cells treated with zinc sulfate. Based on the known estimates of zinc concentrations at the luminal surface of enterocytes $(80 \mu \mathrm{M})$, for our experiments we selected zinc concentration of $100 \mu \mathrm{M}$, which has already been reported as inhibitory towards colon cancer cells and which may be very easily achieved with directed zinc supplementation $(6,12)$. We found that zinc at a concentration of $100 \mu \mathrm{M}$ induces changes in the cytoskeletal integrity of microtubules, promotes loss of F-actin and vimentin and alters the expression of E-cadherin and $\beta$ catenin. In addition, these effects are accompanied by decreased motility and invasiveness of the examined cells.

\section{Materials and Methods}

\section{Chemicals}

Zinc sulfate; 4',6-diamidino-2-phenylindole (DAPI), phalloidin-TRITC, deoxyribonuclease I, Alexa Fluor-488 conjugate and Triton-X were purchased from Sigma-Aldrich 
(Prague, Czech Republic). Antibodies were acquired from: monoclonal mouse anti- $\alpha$-tubulin (Exbio, Prague, Czech Republic), monoclonal mouse anti-vimentin (Dako, Glosstrup, Danemark), monoclonal mouse anti-E-cadherin and monoclonal mouse anti- $\beta$-catenin (Sigma-Aldrich, Prague, Czech Republic). Secondary antibodies were IgG anti-mouse conjugated with Alexa Fluor 488 (1:250) Molecular Probes, Inc. Eugene, USA. All other chemicals were of the highest analytical grade.

\section{Cell line}

The human colon cancer cell line SW480 (ATTC, No. CCL-228, Rockville, U.S.A) was grown in a humidified $5 \%$ $\mathrm{CO}_{2}$ atmosphere at $37{ }^{\circ} \mathrm{C}$ in Dulbecco's modified Eagle's medium - DMEM (Gibco, Prague, Czech Republic) supplemented with 10\% fetal bovine serum (Gibco, Prague, Czech Republic), penicillin G (100 U/ml) and streptomy$\operatorname{cin}(100 \mu \mathrm{g} / \mathrm{ml})$.

\section{Proliferation and metabolic activity}

Proliferation and metabolic activity of SW480 cells exposed to zinc was measured using an established WST-1 method as described earlier (17).

\section{Chemiluminescent quantitation of DNA synthesis}

Estimation of DNA synthesis in control and zinctreated cells was carried out as described previously (17). Briefly, cells at a concentration of 30,000 cells/well in 200 $\mu 1$ of DMEM containing $10 \%$ fetal bovine serum were plated in black 96-well microtiter plates, with the first column of wells representing blank. The cells were allowed to settle overnight at $37{ }^{\circ} \mathrm{C}$ and in $5 \% \mathrm{CO}_{2}$. Next, cultures were exposed to zinc and at given time intervals treated according to protocol supplied by manufacturer. Chemiluminescence was measured using a multiplate reader TECAN SpectraFluor Plus (TECAN Austria GmbH, Grödig, Austria). For all measurements, the integration time was $1000 \mathrm{~ms}$ and gain 130. The results in relative light units (RLU) were expressed as a percentage of control.

\section{Immunofluorescence}

Cover slips with control and treated cultures were fixed with $2 \%$ formaldehyde, rinsed three times with phosphate saline buffer with Triton X (PBS-T) and blocked with 5\% milk for $30 \mathrm{~min}$ at $25^{\circ} \mathrm{C}$. Next, primary antibodies against $\alpha$-tubulin (1:100) and vimentin (1:100) were added to the cells and the samples were incubated for $60 \mathrm{~min}$ at $25^{\circ} \mathrm{C}$. The slides were then rinsed three times with PBS, a secondary antibody was added, and the cells were incubated for $60 \mathrm{~min}$ at $20^{\circ} \mathrm{C}$. The specimens were optionally post-labeled with DAPI, mounted into SlowFade ${ }^{\circledR}$ medium (Molecular Probes, Inc. Eugene, U.S.A.) and examined under a fluorescence microscope Nikon Eclipse E 400 (Nikon Corporation, Kanagawa, Japan) with the digital color matrix camera COOL 1300 (VDS, Vosskühler, Germany). Immunopositivity was analyzed by the software LUCIA DI Image
Analysis System LIM (Laboratory Imaging Ltd., Prague, Czech Republic) in at least 1000 cells per sample. In all experiments, the system of immunological control was employed to avoid false positives or negative staining reactions.

\section{F-actin and G-actin measurements}

SW480 cells $(10,000$ cells/well) were seeded into 96well plates and allowed to grow overnight at $37{ }^{\circ} \mathrm{C}$ and $5 \%$ $\mathrm{CO}_{2}$. The next day, the cultivation medium was replaced by a medium supplemented with zinc and its effect on F- and G-actin was evaluated after $12 \mathrm{~h}$ exposure as described previously (16).

\section{Migration assay}

Migration was evaluated by a wound healing assay. Briefly, SW480 cells were plated into the Petri dishes and allowed to grow to the full confluence. Next, using a blunted micropipette tip, a narrow line was scraped on the colonic cells monolyer. After several rinsings with warm DMEM medium, the culture was exposed to zinc over $12 \mathrm{~h}$. Cell migration was recorded at time points indicated in the Results. Resulting images were analyzed by the automatic analysis system LUCIA DI Image Analysis System LIM (Laboratory Imaging Ltd., Prague).

\section{Invasion assay}

Invasion of SW480 cells following zinc treatment was evaluated using a modified Boyden chamber $(8 \mu \mathrm{m}$ pores, membrane coated with Matrigel - Becton Dickinson, Bedford, U.S.A). Cells were plated in the upper compartment at a concentration of $1 \mathrm{x} 10^{5} / \mathrm{ml}$ in medium with or without zinc sulfate and allowed to migrate for $12 \mathrm{~h}$. Noninvasive cells were removed from the upper chamber with a cotton swab and invasive cells adherent to the underside of the filter were fixed with $4 \%$ formaldehyde and stained with Giemsa solution. The number of cells was determined by automatic analysis system LUCIA DI Image Analysis System LIM (Laboratory Imaging Ltd., Prague).

\section{Western blot analysis}

Zinc-treated and control cells were harvested at different time intervals with trypsin, washed with PBS and centrifuged ( $\left.1000 \mathrm{rpm}, 5 \mathrm{~min}, 4^{\circ} \mathrm{C}\right)$. The resulting pellet was resuspended in $5 \mathrm{ml}$ of ice-cold lysis buffer $(137 \mathrm{mM} \mathrm{NaCl}$, $10 \%$ glycerol, $1 \%$ n-octyl- $\beta$-D-glucopyranoside, $50 \mathrm{mM}$ NaF, $20 \mathrm{mM}$ Tris, $1 \mathrm{mM}$ sodium orthovanadate, Complete TMMini).

The whole cell lysates were boiled for $5 \mathrm{~min} / 95^{\circ} \mathrm{C}$ in SDS sample buffer (Tris- $\mathrm{HCl} \mathrm{pH}$ 6.81, 2-mercaptoethanol, $10 \%$ glycerol, SDS, $0.1 \%$ bromphenol blue) and thereafter they were loaded onto a $12 \% \mathrm{SDS} /$ polyacrylamide gel. Each lysate contained an equal amount of protein $(30 \mu \mathrm{g})$ as determined by BCA assay. After electrophoresis, proteins were transferred to a PVDF membrane ( $100 \mathrm{~V}, 60 \mathrm{~min})$ and incubated at $25{ }^{\circ} \mathrm{C}$ for $1.5 \mathrm{~h}$ with a solution containing $5 \%$ 
nonfat dry milk, $10 \mathrm{mM}$ Tris- $\mathrm{HCl}$ ( $\mathrm{pH} 8.0), 150 \mathrm{mM}$ sodium chloride, and $0.1 \%$ Tween 20 (TBST). Membranes were incubated with primary antibodies (anti- $\alpha$-tubulin, 1:500, anti-E-cadherin, 1:500 and anti- $\beta$-catenin, 1:750) at $4{ }^{\circ} \mathrm{C}$ overnight followed by five $6 \mathrm{~min}$ washes in TBST. Next, the blots were incubated with secondary peroxidase-conjugated antibodies $\left(1: 1000,1 \mathrm{~h}, 25^{\circ} \mathrm{C}\right)$, washed with TBST and the signal was developed with a chemiluminescence (ECL) detection kit (Boehringer Mannheim-Roche, Basel, Switzerland).

\section{Statistics}

Statistical analysis was carried out with the statistical program GraphPad Prism (GraphPad Software, Inc. San
Diego, U.S.A.). We used a one-way Anova test with Dunnett's post test for multiple comparisons. Results were compared with control samples, and means were considered significant if $\mathrm{P}<0.05$.

\section{Results}

\section{The effect of zinc on proliferation and metabolic activity of colon cancer cells}

Using the two established methods of measurement of cell proliferation and metabolic activity, we assessed the dose-dependent effects of zinc sulfate in SW480 malignant colonic cells during $24 \mathrm{~h}$ of treatment. As shown in Fig. 1A, zinc at concentrations higher than $100 \mu \mathrm{M}$ induced inhibi-
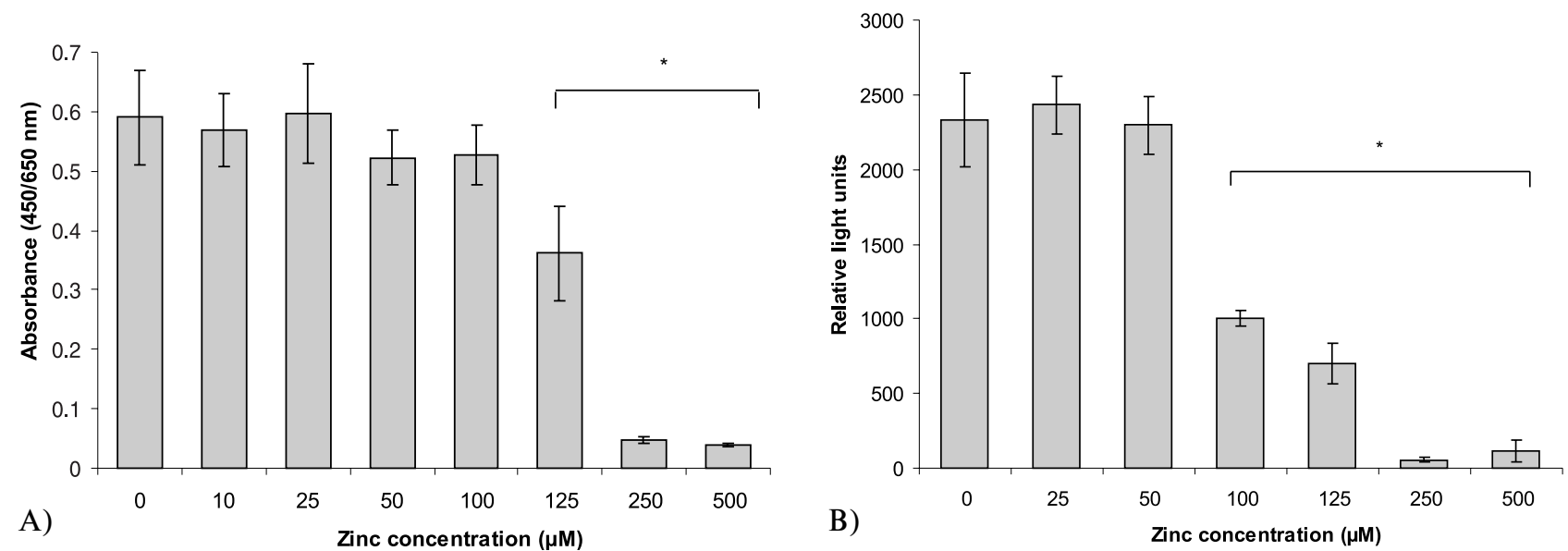

Fig. 1: Proliferation and metabolic activity of SW480 cells treated with $100 \mu \mathrm{M}$ zinc sulfate during $24 \mathrm{~h}$. (A) Metabolic activity determined by WST-1 assay (B) DNA synthesis estimated by incorporation of BrdU. Cells were treated to different concentrations of zinc during $24 \mathrm{~h}$ and individual assays were carried out as described in the Material and Methods section. Values represent the mean $\pm \mathrm{SD}$ of three different experiments. ${ }^{*} \mathrm{P}<0.05$ with one way-Anova test and Dunnett's post test for multiple comparisons.
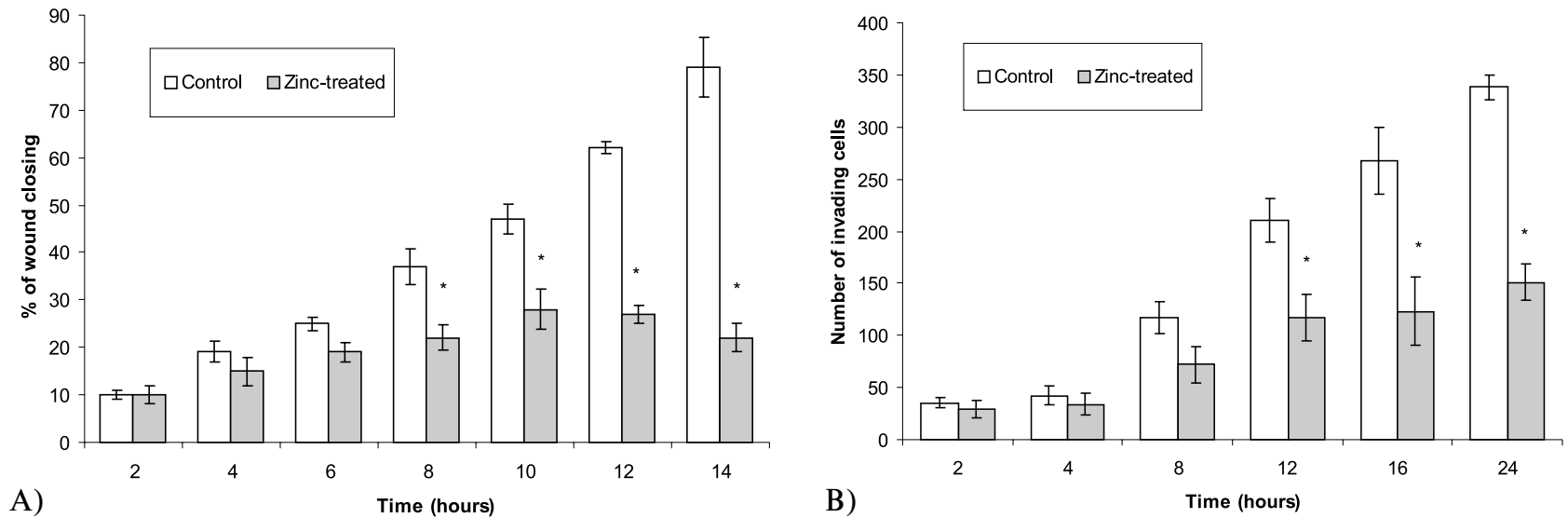

Fig. 2: Migration and invasiveness of SW480 cells treated with $100 \mu \mathrm{M}$ zinc sulfate during $24 \mathrm{~h}$. (A) Migration was determined by wound-healing assay (B) Invasiveness was measured by matrigel assay. Cells were treated with $100 \mu \mathrm{M}$ zinc during $24 \mathrm{~h}$ and individual assays were carried out as described in the Material and Methods section. Values represent the mean $\pm \mathrm{SD}$ of three different experiments. ${ }^{*} \mathrm{P}<0.05$ with one way-Anova test and Dunnett's post test for multiple comparisons. 
tion of metabolic activity in SW480 cells. On the other hand, estimation of DNA synthesis in thus treated cells revealed that zinc-dependent antiproliferative effects are detectable even at concentrations which are lower than 100 $\mu \mathrm{M}$ (Fig. 1B). Moreover, at this concentration range some morphological alterations were observed with individual cells and there was an overall change in the distribution and dynamics (motility) of cellular populations as revealed by time-lapse studies (data not shown).

\section{The effect of zinc on SW480 motility and invasiveness}

Treatment with $100 \mu \mathrm{M}$ zinc of SW480 cells which are motile and invasive significantly decreased their motility as quantified by wound healing assay. On the other hand, invasiveness was not completely prevented although it decreased significantly as well (Fig. 2A and B).

\section{Zinc induces rearrangement of the microtubular network and its later loss in treated SW480 cells}

In order to determine the effect of zinc on the microtubular network in malignant colonic SW480 cells, we investigated its morphology as well as the content after treatment with $100 \mu \mathrm{M}$ zinc sulfate. Fig. 3 illustrates that during the first $12 \mathrm{~h}$ of exposure, typical microtubular cables shortened and formed numerous aggregates in the cytoplasm of cells. This microtubular aggregation was also accompanied by a transition of some SW480 cells shape
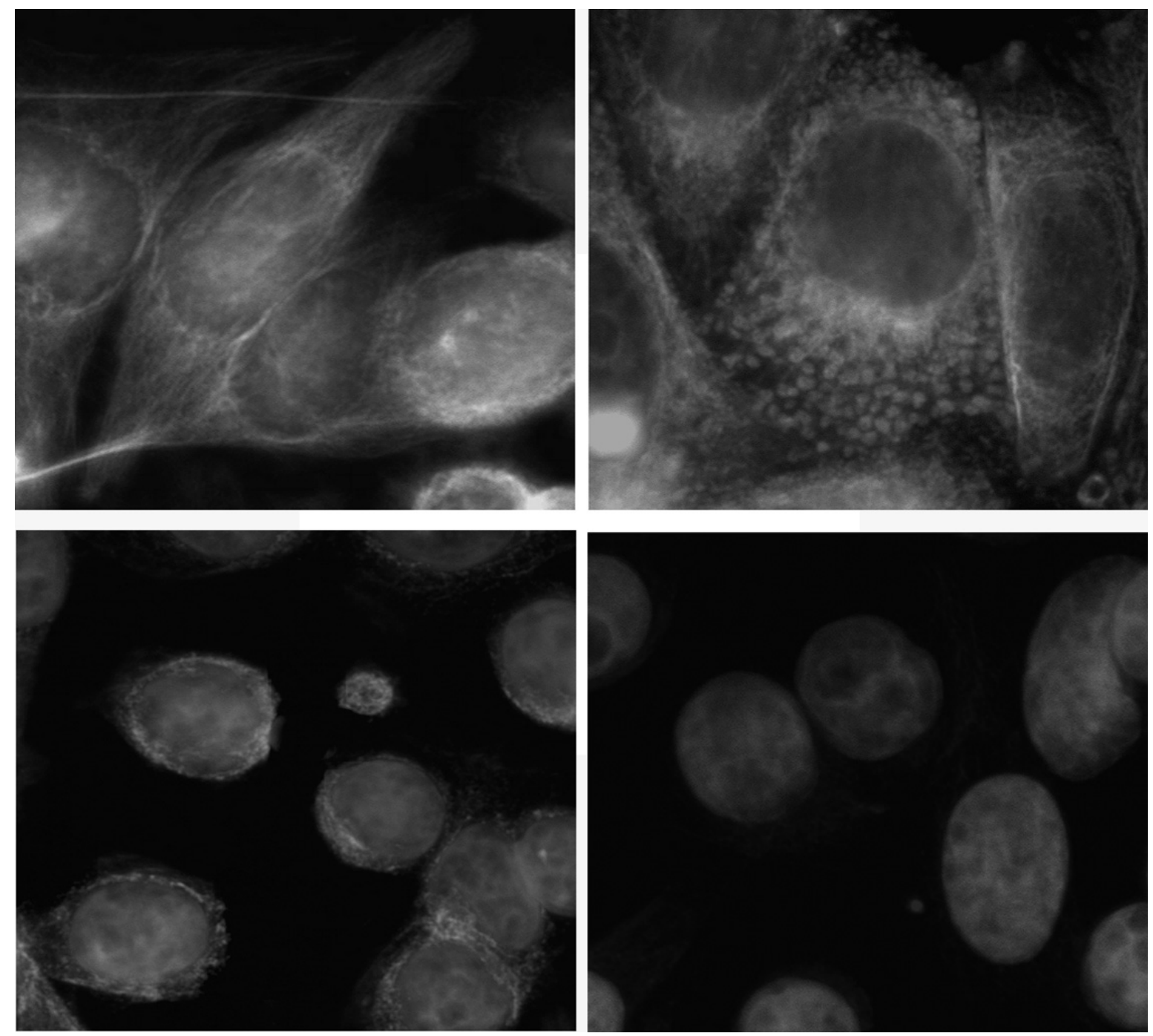

Fig. 3: Effect of zinc $(100 \mu \mathrm{M})$ on topography of $\alpha$-tubulin and vimentin in SW480 cells during 12 h. Analyzed markers were visualized by means of immunofluorescence as described in the Material and Methods section. (A) Arrangement of $\alpha$-tubulin network in control SW480 cells, (B) $\alpha$-tubulin clumping in SW480 cells treated with $100 \mu \mathrm{M}$ zinc at $12 \mathrm{~h},(\mathrm{C})$ Expression of vimentin in control SW480 cells (D) loss of vimentin expression in SW480 cells treated with $100 \mu \mathrm{M}$ zinc at $16 \mathrm{~h}$. Fluorescence 600x. Bar $10 \mu \mathrm{m}$. 
into more epithelial-like. Quantitative analysis of microtubular network by immunoblotting showed a significant loss of the microtubules at $18 \mathrm{~h}$ of treatment (Fig. 4).

\section{The effect of zinc on E-cadherin, $\beta$-catenin and vimentin}

Considering the effect of zinc on the cytoskeletal system in SW480 cells, we next investigated the expression of molecules which are known to mediate adhesion, motility and invasiveness in human epithelial carcinoma cell lines. In Fig. 4, it is shown that in SW480 cells zinc treatment first decreased the expression of E-cadherin and later completely abolished it. In addition, in the same cells zinc induced accumulation of $\beta$-catenin, which peaked at $16 \mathrm{~h}$ of treatment. On the other hand, the expression of vimentin, which typically localizes to the perinuclear and nuclear regions of the cell (Fig. $3 \mathrm{C}$ ) decreased in zinc-exposed cells and at later treatment periods almost disappeared $(16 \mathrm{~h}-$ Fig. 4D).

$0 \mathrm{~h}$

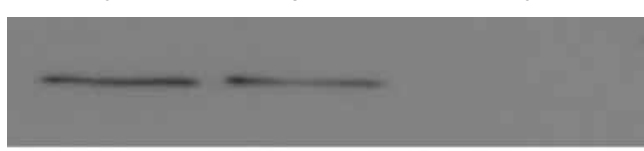

$\beta$-catenin

$\alpha$-tubulin
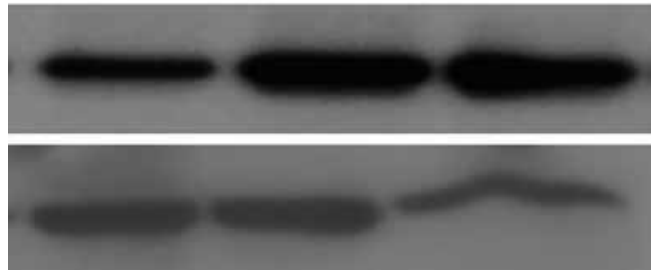

Fig. 4: Changes in expression of E-cadherin, $\beta$-catenin and $\alpha$-tubulin of SW480 cells treated with $100 \mu \mathrm{M}$ zinc for $16 \mathrm{~h}$. Treated cells were harvested and the levels of the followed proteins were determined by means of immunodetection as described in the Material and Methods section. Experiment was repeated thrice.

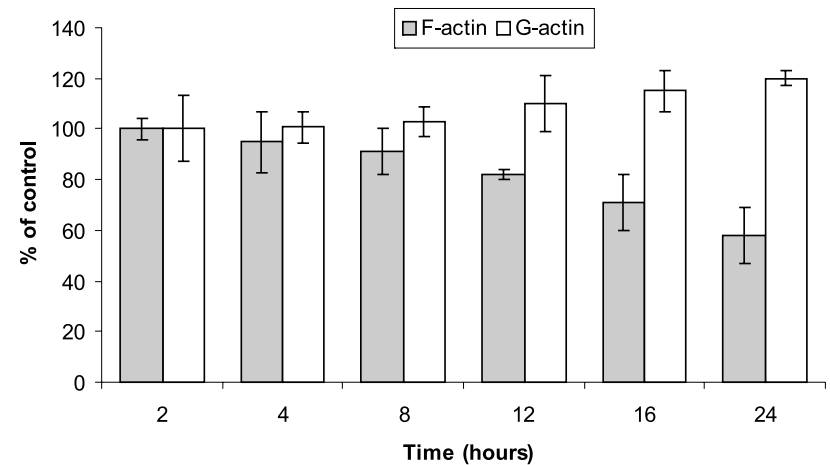

Fig. 5: Effect of $100 \mu \mathrm{M}$ zinc on F- and G-actin levels of SW480 cells during $24 \mathrm{~h}$. Analysis was carried out by fluorimetric microplate assay. Values represent the mean \pm SD of three different experiments. ${ }^{*} \mathrm{P}<0.05$ with one way-Anova test and Dunnett's post test for multiple comparisons.

\section{Changes in $F$ - and G-actin content in treated SW480 cells}

To gain complete insight into the effect of zinc on the cytoskeleton of SW480 cells, we measured F- and G-actin levels during $24 \mathrm{~h}$ exposure with $100 \mu \mathrm{M}$ zinc sulfate. Fig. 5 illustrates that F-actin content in treated cells markedly decreased; however, this decrease became significant only at later treatment periods ( $12 \mathrm{~h}$ and longer). G-actin levels representing non-polymerized actin pools within the cell increased at later observed periods too. Still, this increase was slow and did not match the trend observed in the case of F-actin.

\section{Discussion}

Although arising from epithelial tissues, colon carcinoma cells undergo a series of genetic changes which drive their phenotypic conversion including, among others, epithelial-mesenchymal transition. The leading feature of this transition is the rearrangement of the cytoskeleton and changed expression of various molecules mediating migratory, invasive as well as metastatic properties of these cells (1).

The SW480 cell line was derived from human adenocarcinoma of the colon and represents a motile and invasive stage of colorectal cancer. These cells house mutations in critical signaling pathways such as WNT/ $\beta$-catenin, express truncated APC protein and upregulate the expression of several other proteins, including intermediate filament vimentin $(10,19)$. Together with its isogenic partner, a highly metastatic SW620 cell line, these cells prove to be an excellent model system where specific molecular events mediating biological processes can be studied (9). Using this system, we wanted to study interactions between advanced colon carcinoma and zinc.

Zinc is an important cell constituent and signaling molecule. Its role in the maintenance of cellular homeostasis as well as in the protection of cells against stress influence is widely recognized (4). Colonic epithelial mucosa undergoes continuous renewal and it is therefore sensitive to optimal zinc concentrations, which are estimated to be approximately $80 \mu \mathrm{M}$. Still, the particular physiological functions of zinc in this milieu have not been elucidated owing to technical difficulties in obtaining and long-term maintenance of normal colonocytes. Our current knowledge is thus only indirect; i.e. acquired from studies on the effects of zinc supplementation in zinc-deficiencies such as inflammatory bowel disease and others (3). On the other hand, it has been demonstrated that externally supplied zinc inhibits the growth and proliferation of several types of tumor cells, including colon cancer cells $(5,7,11)$. Particularly interesting appears to be the ability of zinc to inhibit colon cancer cells proliferation via a direct effect on the cytoskeleton, in particular microtubules (6). The studies published so far clearly indicate that externally supplemented zinc has concentration-dependent effects on the prolifera- 
tion of malignant colonocytes; lower concentrations (10-80 $\mu \mathrm{M})$ stimulate their growth, while higher concentrations (100-500 $\mu \mathrm{M}$ ) inhibit it (13). In the present study we show that the concentration of zinc reported to have this effect $(100 \mu \mathrm{M})$ does not influence the metabolic activity of SW480 cells, although it temporarily decreases DNA synthesis, which does not entirely confirm the earlier report (6). The reason for this partial discrepancy may be in the different zinc forms used as well as due to the varying sensitivity of the cell proliferation assays. While the effect of zinc on the proliferation of invasive colon cancer cells needs to be further elucidated, its interaction with the cytoskeleton might prove influential for other biological properties of advanced colon cancer cells; e.g., migration and invasion. Our data acquired from the wound-healing assay and Matrigel invasion assay fully support this notion despite the fact that zinc-treated SW480 cells were not fully prevented from migration and invasion. This may be explained by the fact that zinc is required for the optimal functioning of many proteins, of which some mediate migration and invasion. Thus, paradoxically, increased zinc concentrations might inhibit cell motility and invasion but also simultaneously prevent their full abrogation by its increased availability.

In order to elucidate the mechanisms underlying zincdependent inhibition of SW480 motility and invasion, we investigated several selected involved cytoskeletal components.

Microscopical as well as quantitative studies showed that zinc depletes E-cadherin and vimentin pools and induces the rearrangement and subsequent loss of tubulin and F-actin in invasive colon cancer cells. Conversely, in zinc-exposed cells the expression of $\beta$-catenin increases. Presently, it is not known whether our observed depletion or accumulation of the above mentioned molecules in this model is due to their zinc-promoted degradation or suppression (stimulation) of their expression. It is likely that both and perhaps some further mechanisms are involved in individual cases. Thus we may hypothesize that for instance in the case of actin filaments, it is a combination of degradation and other mechanism(s), since the ratio of polymerized and nonpolymerized actin decreased only partially in zinc-treated cells. It does not apply, however, for other studied proteins, since their loss was preceded by significant successive changes in their topography. Moreover, zinc clearly increased the accumulation of $\beta$-catenin in SW480 cells, which seems to be in stark contrast with its suggested inhibitory role. Currently, we have no plausible explanation for this phenomenon; however, there are some putative factors which may provide more insight into this problem, such as the effect of zinc on APC protein, which is known to interact with microtubules, actin as well as with $\beta$-catenin (6). Apparently, in future studies the expression of all relevant genes and their changes following treatment with zinc needs to be followed at both mRNA and protein levels.
Zinc is generally known for multilayered effects within exposed cells and that is why it will be very difficult to determine whether there are major targets of its activities or if its effects are not target-specific but rather universal. To our knowledge, spatial and temporal changes concomitant with decreased cell motility and invasiveness of SW480 cells suggest the existence of at least two graduated mechanisms. The first might represent an early stage of the increased zinc-cell interaction where zinc ions would act on cell membranes, their constituents and associated signaling pathways, leading to changes in localization and amount of some adhesion complexes such as cadherin-catenin. It has been reported that zinc inhibits proliferation of HT-29 cells via ERK-dependent cascade (13). This cascade may well be involved here too although a link between, for instance, Ecadherin expression, localization and loss and this cascade still remains unclear. Zinc-dependent alterations of the cell membrane and, for instance, adhesion of malignant colonic cells, will then precipitate a second stage where zinc, by acting on several cytoskeletal components or mediating changes in the transcription of selected genes, finally impairs cell motility, migration and invasion. Both mechanisms seem to us as forming a mutually potentiating system that contains several feedback-amplification loops.

These results not only support earlier studies but also add a new dimension to general zinc biology and its involvement in the regulation of cell migration and invasion.

\section{Conclusion}

As well as inhibiting malignant colonic cells SW480 growth and proliferation, zinc may firstly influence their motility and invasiveness by acting both directly and possibly indirectly on several components of the cytoskeleton, such as E-cadherin, $\beta$-catenin, vimentin, $\alpha$-tubulin and actin. These results emphasize the possible multitudinous role of zinc in the process of colon cancer development and hint at the potential of this element in prevention of colorectal carcinoma.

\section{Acknowledgement}

This work was supported by the Ministry of Education Research Project MSM 0021620820.

\section{References}

1. Bellovin DI, Bates RC, Muzikansky A, Rimm DL, Mercurio AM. Altered localization of p120 catenin during epithelial to mesenchymal transition of colon carcinoma is prognostic for aggressive disease. Can Res 2005; 65:10938-45.

2. Buda A, Pignatell M. Cytoskeletal network in colon cancer: from genes to clinical application. Int J Biochem Cell Biol 2004; 36:759-65.

3. Cario E, Jung S, Harder D, Heureuse J et al. Effects of exogenous zinc supplementation on intestinal epithelial repair in vitro. Eur J Clin Invest 2000; 30:419-28.

4. Fraker PJ, Telford WG. A reappraisal of the role of zinc in life and death decisions of cells. Proc Soc Exp Biol Med 1997; 215:229-36.

5. Iitaka M, Kakinuma S, Fujimaki $\mathrm{S}$ et al. Induction of apoptosis and necrosis by zinc in human thyroid cancer cell lines. J Endocrinol 2001; 169:417-24.

6. Jaiswal AS, Narayan S. Zinc stabilizes adenomatous polyposis coli (APC) protein levels and induces cell cycle arrest in colon cancer cells. J Cell Biochem 2004; 93:345-57. 
7. Klein $\mathrm{C}$, Creach $\mathrm{K}$, Irintcheva V, Hughes $\mathrm{KJ}$, Blackwell PL, Corbett JA, Baldassare JJ. Zinc induces ERK-dependent cell death through a specific Ras isoform. Apoptosis 2006; 11:1933-44.

8. Lansdown AB. Zinc in the healing wound. Lancet 1996; 347:706-7.

9. Leibovitz A, Stinson JC, McCombs WB $3^{\text {rd }}$, McCoy CE, Mazur KC, Mabry ND Classification of human colorectal adenocarcinoma cell lines. Cancer Res 1976; 36:4562-9.

10. McInroy L, Maatta A. Down-regulation of vimentin expression inhibits carcinoma cell migration and adhesion. Biochem Biophys Res Commun 2007; 360:109-14.

11. Park K-S, Ahn Y, Kim J-A, Yun M-S, Seong BL, Choi K-Y. Extracellular zinc stimulates ERK-dependent activation of $\mathrm{p} 21 \mathrm{Cip} / \mathrm{WAF} 1$ and inhibits proliferation of colorectal cancer cells. Br J Pharmacol 2002; 137:597-607.

12. Park K-S, Lee N-G, Lee K-H, Seo JT, Choi K-Y. The ERK pathway involves positive and negative regulations of HT-29 colorectal cancer cell growth by extracellular zinc 10. 1152/ajpgi.00047.2003. Am J Physiol 2003; 285:G1181-88.

13. Park KS, Jeon SH, Oh JW, Choi KY. p21Cip/WAF1 activation is an important factor for the ERK pathway dependent anti-proliferation of colorectal cancer cells. Experimental \& molecular medicine 2004; 36:557-62.

14. Potter JD. Colorectal cancer: molecules and populations. J Natl Cancer Inst 1999; 91:916-32.

15. Prasad AS, Kucuk O. Zinc in cancer prevention. Cancer metastasis reviews 2002; 21:291-5.

16. Rudolf E, Červinka M. Cytoskeletal changes in non-apoptotic cell death. Acta Medica (Hradec Kralove) 2006; 49:123-8.

17. Rudolf E, Cervinka M. The role of intracellular zinc in chromium (VI)-induced oxidative stress, DNA damage and apoptosis. Chem Biol Interact 2006; 162:212-27.

18. Song MK, Heng MC, Rolandelli R, Ament ME, Heng MK. Possible link between zinc intake and colon cancer. J Natl Cancer Inst 1993; 85:667-9.

19. Tomita N, Jiang W, Hibshoosh H, Warburton D, Kahn SM, Weinstein IB. Isolation and characterization of a highly malignant variant of the SW480 human colon cancer cell line. Cancer Res 1992; 52:6840-7.

Submitted December 2007.

Accepted January 2008.

\section{Corresponding author:}

Doc. PharmDr. Emil Rudolf, Ph.D., Charles University in Prague, Faculty of Medicine in Hradec Králové, Department of Medical Biology and Genetics, Šimkova 870, 50038 Hradec Králové, Czech Republic, e-mail: rudolf@lfhk.cuni.cz 